\title{
Physiological and Anatomical Consequences of Infraorbital Nerve Transection in the Trigeminal Ganglion and Trigeminal Spinal Tract of the Adult Rat
}

\author{
William E. Renehan, ${ }^{1}$ Bradley G. Klein, ${ }^{2}$ Nicolas L. Chiaia, ${ }^{3}$ Mark F. Jacquin, ${ }^{4}$ and Robert W. Rhoades ${ }^{3}$ \\ 'Department of Anatomical Sciences and Neurobiology, Health Sciencos Conter, University of Louisville School of \\ Medicine, Louisville, Kentucky 40292, 2Department of Neuroscience, New York College of Osteopathic Medicine, Old \\ Westbury, New York 11568, ${ }^{3}$ Department of Anatomy, School of Osteopathic Medicine and Robert Wood Johnson \\ Medical School, University of Medicine and Dentistry of New Jersey, Piscataway, New Jersey, 08854, and ${ }^{4}$ Department of \\ Anatomy and Neurobiology, St. Louis University School of Medicine, St. Louis, Missouri 63104
}

Single-unit recording and retrograde tracing techniques were used to assess the receptive field properties, topography, and projections of rat trigeminal primary afferent neurons subsequent to transection of the infraorbital (1O) nerve in adulthood. Four hundred and fifty-eight units were recorded in the trigeminal ganglion ipsilateral to nerve section. Of these, $66.6 \%$ had 10 receptive fields. Thirty percent responded to innocuous stimulation of vibrissae, $39.1 \%$ to guard hair deflection, $8.2 \%$ to gentle indentation or stretch of the skin, and $22.3 \%$ to noxious stimuli (compared to $77.2 \%$ vibrissa, $12.0 \%$ guard hair, $4.5 \%$ skin, and $6.3 \%$ noxious in normal animals). An additional 15 units were driven by a stimulating electrode placed on the 10 nerve proximal to the site of the lesion but had no receptive field. Of the cells with vibrissa receptive fields, $33.3 \%$ were slowly adapting type I (SAI), 6.6\% were slowly adapting type II (SAII), 32.2\% were low velocity rapidly adapting (RA-LV), $20.0 \%$ were high velocity rapidly adapting (RA-HV), and $7.7 \%$ were nociceptive (NX, in normal animals $43.8 \%$ were SAl, $10.3 \%$ SAll, $27.6 \%$ RA-LV, 16.8\% RA-HV, and $1.5 \%$ NX). A number of cells had receptive field properties not seen in normal animals. The single-unit recordings indicated that the topography of mandibular and ophthalmic representations in the ganglion were essentially normal, while the organization of the maxillary region of the ganglion was slightly abnormal.

The ganglion physiology experiments were augmented by records from primary afferents in the trigeminal spinal tract (TrV). Eighty-one (72.2\%) of the 112 fibers recorded in the TrV of normal rats had 10 receptive fields. Of these, $73.2 \%$ responded to innocuous vibrissal stimulation, $14.6 \%$ to guard hair deflection, $8.5 \%$ to gentle indentation of the skin, and $2.5 \%$ to noxious stimuli. Of the 61 vibrissa units, $37.8 \%$ were SAI, $19.7 \%$ SAll, 37.8\% RA-LV, 3.3\% RA-HV, and $1.6 \%$ NX. In adult-lesioned animals, $81(61.3 \%)$ of the recorded fibers

Received Feb. 8, 1988; revised June 17, 1988; accepted June 27, 1988.

We wish to express our appreciation to Ms. Susan Stansel, Mr. Paul Hess, and Ms. Zebetta Allen for their excellent technical assistance. We are especially indebted to Ms. Mary Joshua and Dr. Richard Greenberg for their advice and assistance in the statistical analysis of the data. This work was supported in part by Grants DEO7734, DEO6528, DEO7662, BNS 8515734, NSO7444 and the UMDNJ Foundation.

Correspondence should be addressed to William E. Renehan, Ph.D., at the above address.

Copyright (C) 1989 Society for Neuroscience $0270-6474 / 89 / 020548-10 \$ 02.00 / 0$ had 10 receptive fields. Of this number, $38.2 \%$ responded to vibrissae, $29.6 \%$ to guard hairs, $16.0 \%$ to skin, and $19.7 \%$ to noxious simuli. Of the vibrissa-sensitive units, $16.1 \%$ were SAI, $3.2 \%$ were SAll, $45.2 \%$ were RA-LV, $35.5 \%$ were RA$\mathrm{HV}$, and $3.2 \% \mathrm{NX}$. As in the ganglion recording studies, a number of abnormal receptive fields were documented. The ganglion and $\mathrm{TrV}$ recording studies indicate that transection of the 10 nerve in the adult rat results in an increase in the relative number of nociceptive, guard hair, and high-velocityrapidly adapting units as well as units with absent or unusual receptive fields.

Altered maxillary intradivisional topography was further examined in 6 rats that received injections of different fluorescent tracers or HRP in the A1, A4, E1, and E4 vibrissae. These morphological studies indicated that the mediolateral topography of cells innervating the mystacial pad vibrissae was not maintained in the adult-lesioned animals.

Numerous studies have documented the unpleasant sensations and faulty sensory localization reported by patients recovering from peripheral nerve transections (Hawkins, 1948; McQuillan et al., 1971; Hallin et al., 1981; Orgel, 1982; Mackel et al., 1983, 1985). Surprisingly, most single-fiber recordings from regenerating peripheral nerves have indicated that the majority of cutaneous primary afferents have virtually normal receptive field properties. Mackel et al. (1983, 1985), using percutaneous microneurography to record single-unit activity in human subjects recovering from median or ulnar nerve transection, found that the response thresholds, discharge characteristics, and receptive field properties of most of the axons tested were normal (though the authors failed to identify reinnervated Pacinian corpuscle units in either study). Similarly, Hallin et al. (1981) have shown that regenerating myelinated cutaneous afferents exhibited discharge properties consistent with those recorded in normal subjects, though the conduction velocities were abnormally slow. Comparable results have been obtained in an investigation of baboon glabrous skin reinnervation, with the authors postulating that the regenerating axon possesses a submodality determining factor which causes the axon to supply the same type of receptor originally innervated (Terzis and Dykes, 1980). As discussed previously (see Renehan and Munger, 1986), a number of factors may account for the discrepancy between clinical observations and single-unit recordings. (1) Most single-unit 
studies performed to date have only examined the response of glabrous skin afferents to nerve transection. The response of hairy skin units to dencrvation may differ from that seen in glabrous skin. In one of the few electrophysiological investigations of post-transection reinnervation of hairy skin, Burgess and Horch (1973) documented a number of units with abnormal receptive fields as well as significantly decreased or increased numbers of some receptor types and axons with no receptive fields. (2) Some single-unit physiology studics of the consequences of nerve lesions have utilized innocuous stimuli only. For example, Mackel et al. (1983, 1985), Horch (1979), and Terzis and Dykes (1980) employed noxious stimuli but did not include this category in their results), thus missing a possible increase in the number of nociceptive units. (3) It may not be necessary for a large number of units to be abnormal to cause a patient significant discomfort. (4) Regardless of the accuracy of primary afferent regeneration, permanent postsynaptic alterations may interfere with stimulus perception.

We have previously provided evidence that neonatal infraorbital nerve transection results in abnormal primary afferent receptive fields, altered peripheral and central projections, and unusual ganglion topography (Jacquin and Rhoades, 1983, 1985; Jacquin et al., 1986c; Klein et al., 1987; Rhoades et al., 1987). In the adult rat, this injury has been shown to cause markedly abnormal mystacial vibrissa innervation (Renehan and Munger, 1986), significant trigeminal ganglion cell death (Arvidsson and Aldskogius, 1977; Aldskogius and Arvidsson, 1978), and transganglionic degeneration (Grant and Arvidsson, 1975; Arvidsson, 1979). The purpose of the present study is to use the rat trigeminal system as a highly ordered hairy skin model to examinc the cffccts of adult ncrve transection on the receptive field properties, topography, and peripheral projections of primary afferent neurons.

\section{Materials and Methods}

\section{Ganglion recording experiments}

Ten adult Wistar rats were anesthetized with a mixture of ketamine and xylazine $(37.5 \mathrm{mg}$ ketamine and $5.0 \mathrm{mg}$ xylazine $/ \mathrm{ml} ; 0.1 \mathrm{ml} / 100 \mathrm{~kg}$ ) or ketamine and chlorprothixene $(37.5 \mathrm{mg}$ ketamine and $12.5 \mathrm{mg}$ chlorprothixene $/ \mathrm{ml} ; 0.1 \mathrm{ml} / 100 \mathrm{~kg}$ ) and subjected to left infraorbital nerve transection at the level of the infraorbital foramen. The cutaneous regions innervated by the IO nerve were not damaged during the surgery. No attempt was made to align the proximal and distal stumps of the transected nerve. At least $60 \mathrm{~d}$ after the nerve lesions, the animals were anesthetized with sodium pentobarbital $(60 \mathrm{mg} / \mathrm{kg}$, i.p., supplemented as needed), administered atropine sulfate (1-2 mg/ $\mathrm{kg}$, i.p.), placed on a respirator, and immobilized with gallamine triethiodide $(35 \mathrm{mg} / \mathrm{kg}$, i.p., supplemented hourly). Heart rate was monitored continuously, and the animal's body temperature was maintained with a thermostatically controlled heating pad.

Recordings in 6 animals were made with tungsten microelectrodes, and recordings in 4 rats were made with glass micropipettes.

Experiments with tungsten microelectrodes. The dorsal calvarium was removed on the left side (ipsilateral to the transection), the forebrain aspirated and the trigeminal ganglion exposed. Tungsten microelectrodes (Frederick Haer, impedance $=20-25 \mathrm{M} \Omega$ ) were placed on the ganglion $1.0 \mathrm{~mm}$ caudal to bregma with a stereotaxic electrode manipulator and advanced with a Kopf stepping microdrive. This region of the ganglion is known to contain primarily maxillary and ophthalmic cells. Single units were amplified, displayed, and monitored using standard methods (see Rhoades et al., 1983). Somatosensory simulation was delivered, and receptive fields were carefully documented using previously described methods (Jacquin et al., 1986a, b). Afferent receptor type was categorized according to criteria established by Gottschaldt et al. (1973) for vibrissa afferents and Burgess and Perl (1973) and Brown and Iggo (1967) for nonvibrissa units. An entire battery of stimulation was delivered every $20 \mu \mathrm{m}$ of descent through the ganglion. The depth and receptive field of each well-isolated cell were recorded, and the track terminated when the electrode hit the petrous bone underlying the ganglion.

Tungsten electrodes are advantageous for obtaining a large sample of cells, but are unsuitable for accurately determining antidromic activation and conduction velocity due to large shock artifact. For this information, and to guard against sample bias toward large cells which may bc introduced by using tungsten electrodes, we also used glass micropipettes in a second series of ganglion recording experiments.

Experiments with glass micropipeltes. The dura covering the trigeminal ganglion was carefully incised and reflected and the ganglion kept moist in warm mineral oil. Concentric bipolar stimulating electrodes were placed on the left IO nerve in the orbit (proximal to the site of the lesion) and in the spinal trigeminal nuclcus and tract at the level of the obex. Search stimuli consisted of $30-40 \mathrm{~V}$ monophasic rectangular pulses isolated from ground and delivered at a rate of $1 \mathrm{~Hz}$.

Glass microclectrodes (Sutter, $1.0 \mathrm{~mm}$ inside diameter) were filled with $3.0 \mathrm{M} \mathrm{KCl}$ (resistance, $20-30 \mathrm{M} \Omega$ ) and advanced through the ganglion in $2.5 \mu \mathrm{m}$ steps. An agar solution was applied over the ganglion to reduce circulation and respiration-induced movement. As noted in the previous section, receptive fields were mapped and classified according to the methods of Jacquin et al. (1986a, b), using the criteria of Gottschaldt et al. (1973) for vibrissa afferents and Burgess and Perl (1973) and Brown and Iggo (1967) for nonvibrissa units. The data obtained in ganglion cell recording experiments were compared with that previously reported by Jacquin et al. (1986c).

\section{Brain-stem recording experiments}

In addition to recording from trigeminal primary afferent neurons at the level of the trigeminal ganglion, we also recorded from the central projections of these cells in the trigeminal spinal tract. Nineteen adult rats sustained transection of the left IO nerve as described above. At least $60 \mathrm{~d}$ after the lesion the animals were anesthetized with sodium pentobarbital $(60 \mathrm{mg} / \mathrm{kg}$, i.p.), administered atropine sulfate $(1-2 \mathrm{mg}$, i.p.), placed on a respirator, and paralyzed with gallamine triethiodide $(35 \mathrm{mg} / \mathrm{kg}$, i.p.). The caudal medulla was exposed by retracting the dura over the cerebellomedullary cistern and removing a portion of the occipital bone. The pia-arachnoid was carefully removed and warm mineral oil was applied to the brain stem. Concentric bipolar stimulating electrodes were placed on the ophthalmic-maxillary portion of the trigeminal ganglion $(1.0 \mathrm{~mm}$ caudal to bregma, $2.3 \mathrm{~mm}$ lateral to midline, 9.0-9.5 mm ventral to the surface of the cortex). Beveled glass micropipettes (Microstar; resistance, 50-120 M $\Omega$ ) were lowered into the trigeminal spinal tract and the surface of the medulla covered with $3.0 \%$ agar to minimize movement. Search stimuli were delivered and units recorded, displayed, and characterized as described above.

The data obtained in the brain-stem recording studies of lesioned adult rats was compared with data acquired in identical recording experiments in 6 normal adult rats.

\section{Soma size determination}

To determine the effect of IO nerve transection on the size of the cells giving rise to this nerve, somata were labeled by retrograde transport of HRP. Three normal and 4 adult-lesioned rats were anesthetized with ketamine and chlorprothixene, and placed in a stereotaxic headholder; IO nerves were exposed using an intraorbital approach (Jacquin and Zeigler, 1983). The orbital contents were retracted laterally, and a pipette was filled with $5 \%$ wheat germ agglutinin-conjugated HRP(WGA-HRP; Sigma) and $30 \%$ HRP (Sigma Type VI) was lowered into the IO nerve proximal to the site of the transection and 1.5-2.0 $\mu$ l of the mixture injected over a period of 3-5 min. Care was taken to minimize leakage from the injection site. Following the injection of the tracers, the scalp was sutured and the animals were returned to their cage.

After a survival time of $2-4 \mathrm{~d}$, rats were deeply anesthetized with sodium pentobarbital and perfused according to the method of Rosene and Mesulam (1978). The trigeminal ganglia and its peripheral nerve roots were carefully removed and cut at $25 \mu \mathrm{m}$ on a cryostat. The tissue was reacted for visualization of HRP by the method of Mesulam (1978). Sections were dehydrated, cleared, and coverslipped without counterstaining.

Cell diameters were determined using measurements made from $720 \times$ drawings of labeled somata using a graphics tablet and corrected using the methods described by Smolen et al. (1983) and Klein et al. (1987). 
ALL INFRAORBITAL UNITS
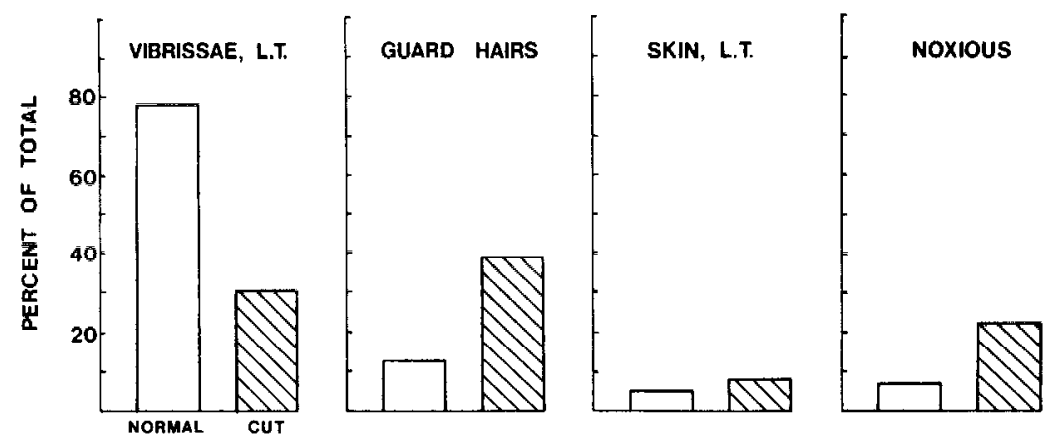

Figure 1. Top, Histograms illustrating the relative percentages of all primary afferent neurons with infraorbital receptive fields recorded in the trigeminal ganglion. Graphs indicate those units that responded to low-threshold vibrissa, guard hair, skin, or noxious mechanical stimuli. For each category, data from normal ganglia (taken from Jacquin et al., 1987) are shown on the left and data from ganglia ipsilateral to adult IO transection are on the right. Bottom. Histograms depicting the relative percentages of units with vibrissa receptive fields only. Data from normal ganglia are taken from Jacquin et al. (1986c)

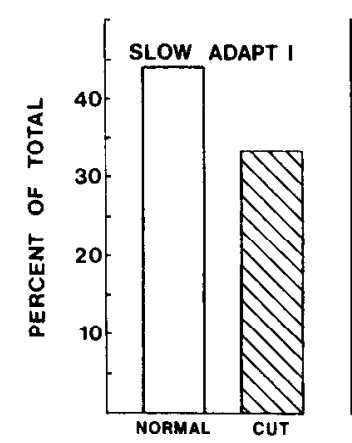

ALL INFRAORBITAL VIBRISSAE UNITS

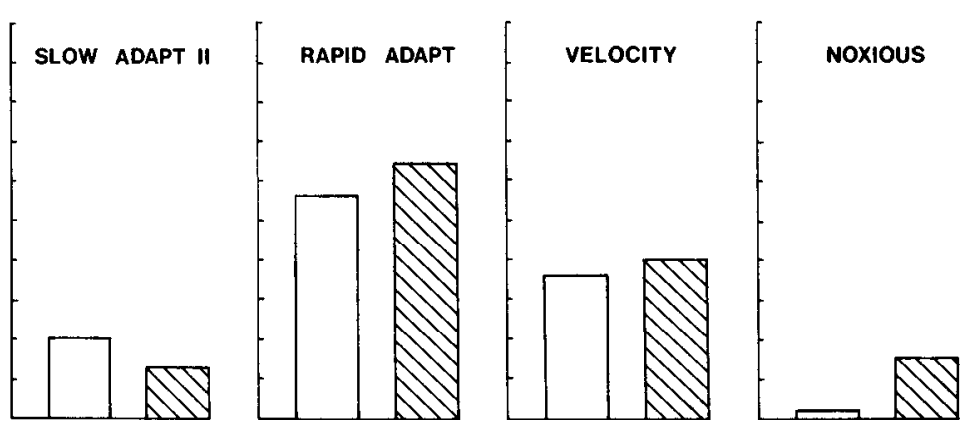

\section{Ganglion topography}

To determine the topography of IO ganglion cells reinnervating the vibrissae of the mystacial pad, selected vibrissae follicles were injected with HRP or fluorescent tracers and the locations of the retrogradely filled cell bodies determined with bright-field and episcopic fluorescence optics. Rats were anesthetized with a combination of chlorprothixene and ketamine. The guard hairs of the mystacial pad were removed with a commercially available depilatory and the animals secured in a stereotaxic headholder. Specific follicles (A1, E1, A4, and E4, see Figs, 7 and 8) were isolated and injected with either True blue (Sigma; $2.5 \%$ in water), diamidino yellow (Dr. Illing $\mathrm{GmBH}$ and Co.; $2.5 \%$ in water), fluorogold (2.0\%, Fluorochrome Inc.), or WGA-HRP (Sigma; $5 \%$ in water) according to the method of Klein and Rhoades (1985). Rats were perfused transcardially with $0.9 \%$ saline followed by $4 \%$ paraformaldehyde (in $0.1 \mathrm{M}$ phosphate buffer, $\mathrm{pH} 7.4$ ) after a $72 \mathrm{hr}$ survival time. Mystacial pads and ganglia were immediately removed and alternate sections processed for either fluorescence or HRP. Sections to be processed for fluorescence were obtained from tissue embedded in O.C.T. compound (Miles Laboratories), frozen in liquid nitrogen, and cut at $25 \mu \mathrm{m}$ in a cryostat. Tissue was plated onto unsubbed slides and coverslipped with mineral oil. Sections to be processed for visualization of HRP reaction product were processed as noted in the previous section with the exception that potassium nitroprusside was omitted from the reaction.

\section{Statistical analysis}

The significance of changes in the relative proportions of cells in the ganglion and brain-stem recording experiments (as compared with values obtained in normal animals) was evaluated using the $\chi^{2}$ test, based on justifications presented by Fleiss (1981) and Mattson (1981). Briefly, both groups (normal and adult-lesioned) were first compared with each other to determine if indeed a significant difference was found between the 2 distributions. This analysis did demonstrate that significant differences between the 2 groups existed $\left(\chi^{2}=245.42\right.$ with 6 degrees of freedom, $p<0.01$, in ganglion recording experiment). We then collapsed the original tables into $2 \times 2$ tables, comparing each experimental group to normal, to define those single categories for which differences were significant.

\section{Results}

\section{Ganglion recording experiments}

A total of 458 ganglion cells ipsilateral to the IO lesion were recorded and characterized. Of these, 245 cells were recorded with tungsten electrodes and 213 with glass. The average encounter rate using tungsten microelectrodes was one unit every $55.4 \mu \mathrm{m}$, and for glass electrodes was one unit every $50.3 \mu \mathrm{m}$. Examination of Figures 2, 3, 5, and 6 reveals that tungsten and glass electrodes isolated a similar range of receptive fields.

Of the 458 trigeminal ganglion cells recorded, 290 (66.6\%) units had IO receptive fields. As indicated in Figure 1,30\% of the IO cells responded to innocuous vibrissal stimulation, $39.1 \%$ to guard hair deflection, $8.2 \%$ to gentle indentation or stretch of skin, and $22.3 \%$ to noxious (strong pinch or deep pressure, with no response to careful stimulation of adjacent territory) stimuli. An additional 15 units were driven by the IO stimulating electrode but had no discernable peripheral receptive field. When this analysis was restricted to units with IO vibrissa receptive fields only, $33.3 \%$ were found to be slowly adapting type I, $6.6 \%$ were slowly adapting type II, $32.2 \%$ were low velocity rapidly adapting, $20.0 \%$ were high velocity rapidly adapting, and $7.7 \%$ were nociceptive-biased (for a description of these receptive fields, see Jacquin et al., 1986a). In our previous receptive field analysis of the ophthalmic-maxillary portion of normal trigeminal ganglia (Jacquin et al., 1986c), using identical procedures, we found that $73.5 \%$ of the recorded cells had 10 receptive fields. Of these, $77.2 \%$ responded to vibrissal stimulation, $12.0 \%$ responded best to guard hair deflection, $4.5 \%$ to gentle skin indentation or stretch, and only $6.3 \%$ responded to noxious stimuli. The relative increase in the number of guard hair and nociceptive units, and the decrease in vibrissa units 
Gang B3

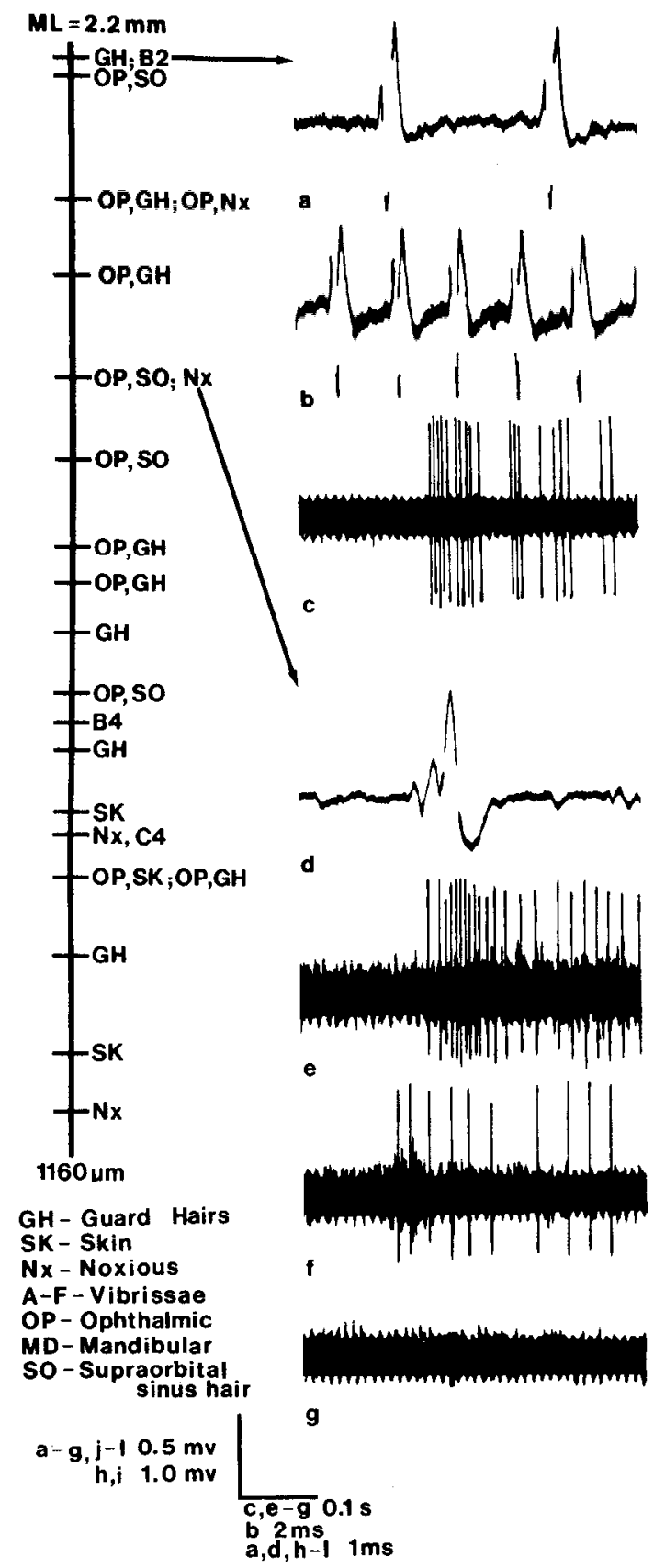

Gang $B 5$

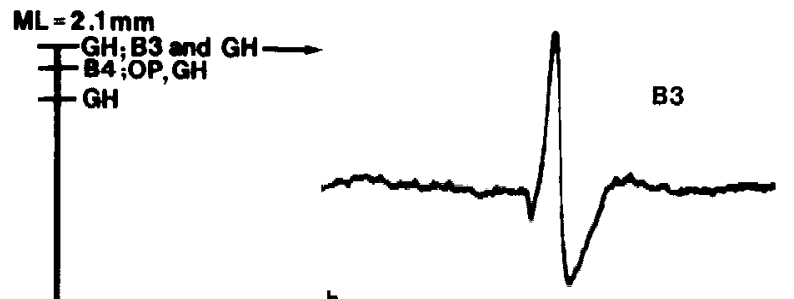

h
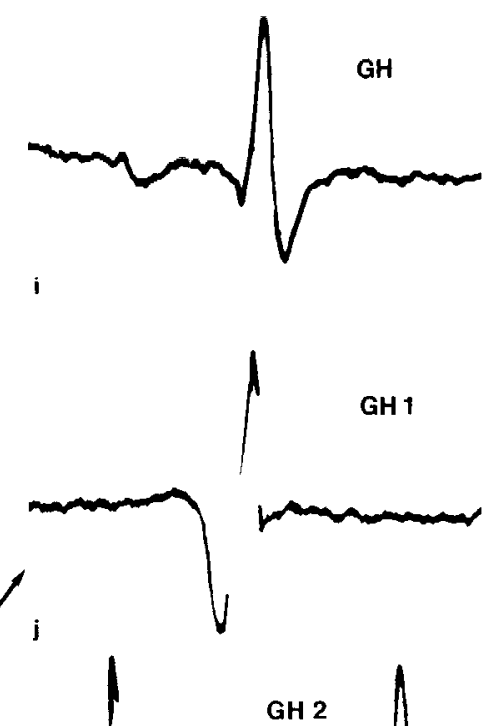

GH 2

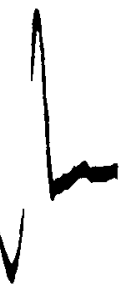

k
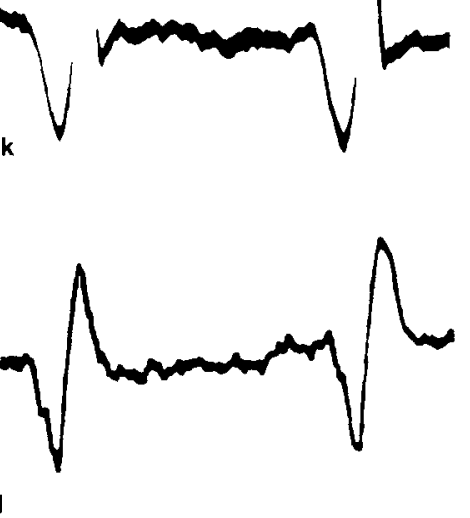

Figure 2. Receptive fields of each unit recorded in penetrations through the deepest portion of the ophthalmic-maxillary region of the trigeminal ganglion in 2 of the animals subjected to transection of the 10 nerve as adults. In each case the electrode was placed 1.0 mm caudal to bregma; the distance of the track from the midline is indicated at the top. Representative response properties of selected units are shown to the right of each track. Oscillographs $A-C$ show the response of a $\mathbf{B} 2$ vibrissa to sustained dorsal deflection ( $A$ and $C$ ) and application of a 512 tuning fork to the shaft of the hair $(B)$. The response of a nociceptive unit to sustained pinch of the skin over the A3 vibrissa is illustrated in $D$ and $E$, while $F$ shows the response to deep pressure and $G$ indicates the lack of response to light stroking of the skin in this region. Oscillographs $H$ and $I$ illustrate the response of a ganglion cell to deflection of the B3 vibrissa $(H)$ or a small group of guard hairs above Al $(I)$. Multiple receptive fields of this type are not found in normal animals. Another multiple receptive field is shown in $J$ and $K$. This ganglion cell was sensitive to deflection of both a long guard hair on the snout $(J)$ and movement of guard hairs above the snout at the midline $(K)$. The waveform of a rapidly adapting El vibrissa afferent is illustrated in $L$.

following nerve transection in adulthood was statistically significant $\left(\chi^{2}=66.07, p<0.01\right.$ for increase in proportion of guard hair cells; $\chi^{2}=35.88, p<0.01$ for increase in noxious units; $\chi^{2}=142.74, p<0.01$ for decrease in vibrissa units). When we restricted our analysis of normal ganglion units to vibrissa-sensitive cells only, we found that $43.8 \%$ were slowly adapting type
I, $10.3 \%$ were slowly adapting type II, $27.6 \%$ were low velocity rapidly adapting, $16.8 \%$ were high velocity sensitive, and only $1.2 \%$ were nociceptive. There was a suggestion that the transection lesion increased the percentage of vibrissa-sensitive nociccptive units, but the low number of cells recorded in this category did not permit valid statistical analysis. 


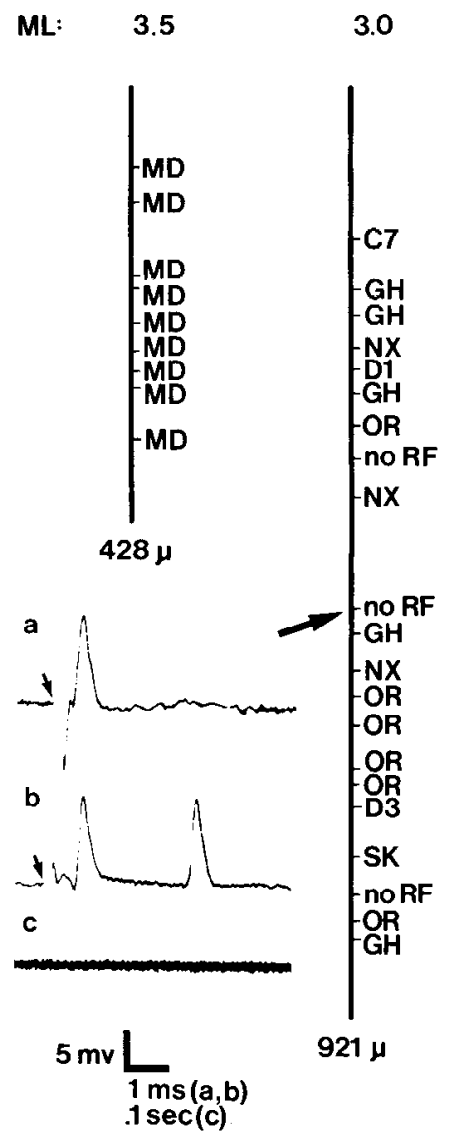

2.5

2.0

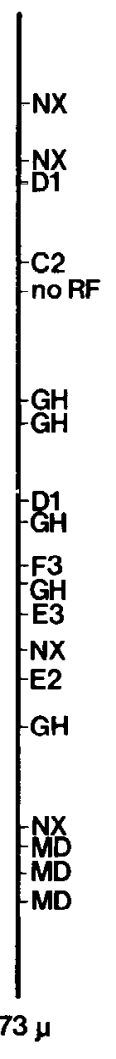

Figure 3. Receptive fields of all the ganglion cells isolated with glass microelectrodes in 4 penetrations through an adult trigeminal ganglion ipsilateral to $1 O$ nerve transection. The placement of the electrode (in millimeters) lateral to the midline is shown at the top of each track. All
In addition to a relative increase in the number of nociceptive and guard hair units, adult IO nerve transection also resulted in a number of ganglion cells with abnormal receptive fields. These unusual units included 5 cells with discontinuous receptive fields ( 2 of these units responded to deflection of more than one vibrissa), a unit that was sensitive to movement of a vibrissa and surrounding guard hairs, and 8 cells that responded only to deep pressure in the region of the $\mathrm{IO}$ foramen. The response properties of 2 of the units with abnormal receptive fields are shown in Figure 2. Panel $h$ in this reconstruction of a tungsten electrode track $2.1 \mathrm{~mm}$ lateral to the midline shows the response of a ganglion cell (encountered $10 \mu \mathrm{m}$ below the surface of the ganglion) to sustained caudal deflection of the B3 vibrissa. This same unit also responded to movement of a small group of guard hairs above the A1 vibrissa (panel $i$ ). Deflection of the intervening guard hairs and vibrissae elicited no response from the unit. Another ganglion cell with a discontinuous receptive field, recorded $880 \mu \mathrm{m}$ below the surface of the ganglion, is illustrated in panels $j$ and $k$. In this case, the unit was rapidly adapting to movement of a pair of long guard hairs on the snout $(j)$, as well as a small group of guard hairs above the snout $(k)$.

tracks were made $1.0 \mathrm{~mm}$ caudal to bregma, and the total depth of each track is indicated at the bottom. The oscillograph depicted in $a$ indicates the response of a ganglion cell with no receptive field to IO nerve stimulation; $b$ illustrates this cell's response to the trigeminal spinal tract stimulating electrode; and $c$ shows lack of response to general lowthreshold stimulation of the mystacial pad with a cotton-tipped swab. $M D$, unit with mandibular receptive field; $O P$, unit with ophthalmic receptive field. All units not indicated by $O P$ or $M D$ had maxillary receptive fields. $G H$, guard hair unit; $O R$, oral unit; $N x$, nociceptive unit; no $R F$, unit with no receptive field but driven by IO and/or spinal tract stimulating electrode; mystacial vibrissa units are shown using standard nomenclature.

ALL INFRAORBITAL UNITS

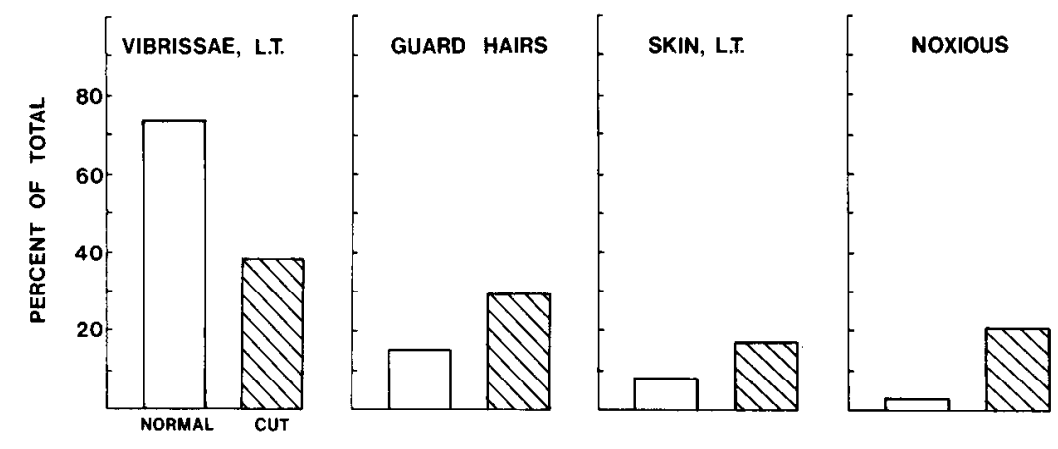

Figure 4. Top, Histograms depicting the relative percentages of all primary afferent neurons with infraorbital receptive fields recorded in the trigeminal spinal tract. Graphs indicate those units that responded to low-threshold vibrissa, guard hair, skin, or noxious mechanical stimuli. Within each category, the left graph illustrates the percentage of units recorded in normal animals and the right shows the percentage recorded in animals subjected to IO transection. Bottom, Ilistograms showing the relative percentages of units with vibrissa receptive fields only.

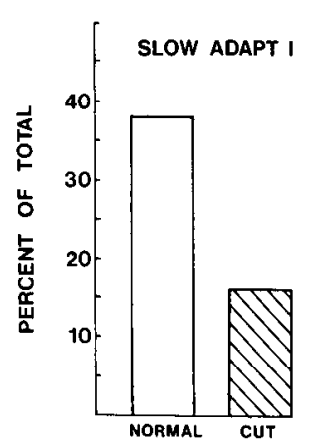

ALL INFRAORBITAL VIBRISSAE UNITS
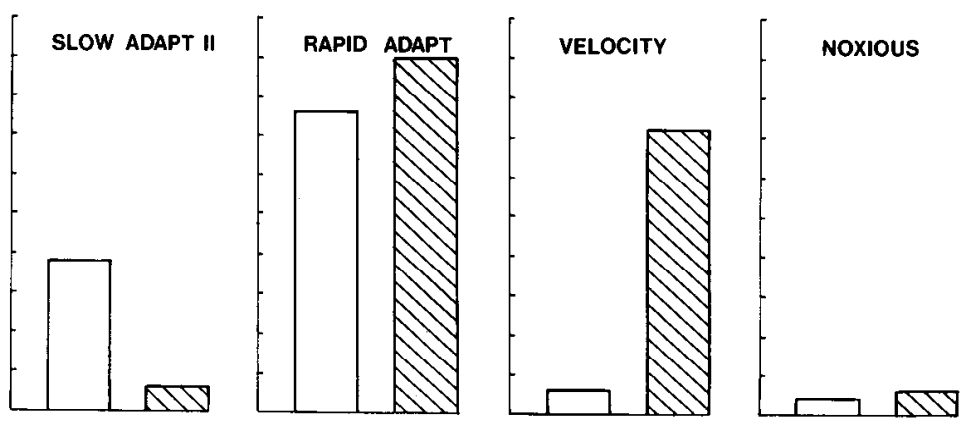


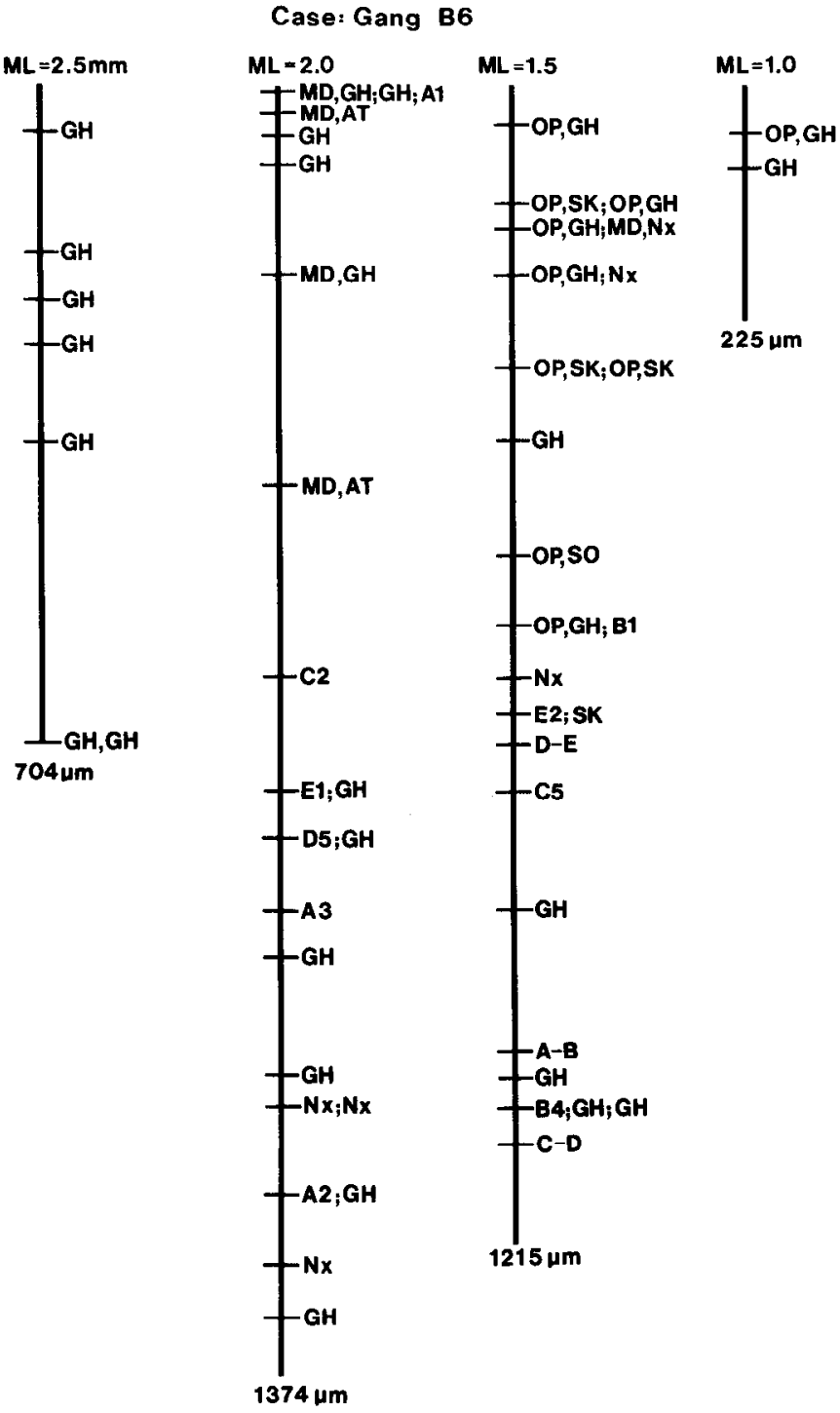

Figure 5. All units isolated with tungsten microelectrodes in 4 penetrations through a trigeminal ganglion ipsilateral to IO nerve transection. The relative depth of each unit is shown as the point of maximum action potential amplitude. Semicolons separate multiple units found at the same depth. The response properties of mandibular and ophthalmic units follow the $M D$ or $O P$ symbol, separated by a comma. All units not accompanied by MD or OP were found in the maxillary region. $S K$, skin; $A T$, auriculotemporal sinus hair; $S O$, supraorbital sinus hair; all other abbreviations are identical to those used in Figure 3.

An example of an axotomized ganglion cell that maintained a central brain-stem projection and a peripheral process which reached the rostral orbit, but did not have a discernable receptive field, is illustrated in Figure 3. This figure depicts the receptive ficlds of all ganglion cells encountered in 4 mediolatcral tracks with glass microelectrodes $1.0 \mathrm{~mm}$ caudal to bregma. The responses of one ganglion cell to IO ( $a, 0.4 \mathrm{msec}$ latency) and spinal trigeminal tract stimulation ( $b, 0.6 \mathrm{msec}$ latency) are also depicted. This cell had no discernable receptive field using the stimuli we employed (lack of response to innocuous stimuli of the mystacial pad with a cotton-tipped swab is shown in $c$ ). A total of 15 of the 213 units recorded in the trigeminal ganglion with glass microelectrodes had no receptive fields.

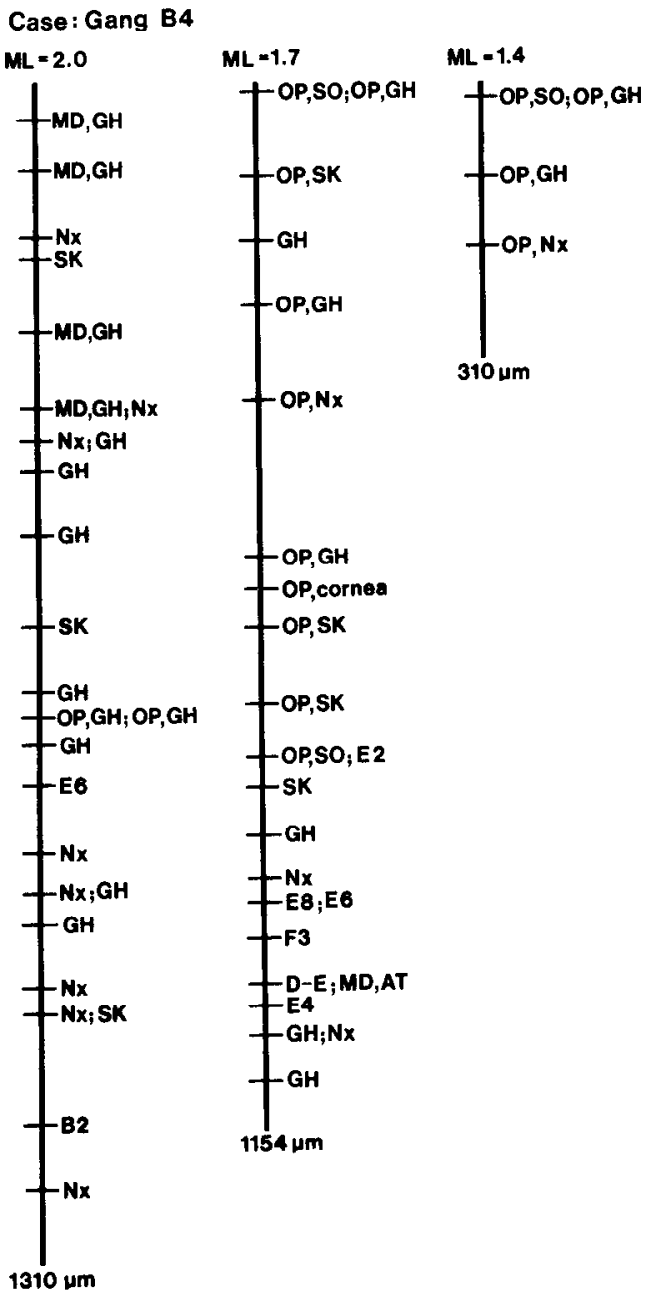

Figure 6. Receptive fields of all units recorded with tungsten microelectrodes in 4 penetrations through an adult trigeminal ganglion ipsilateral to IO nerve transection. All conventions and abbreviations are identical to those used in Figure 5.

\section{Brain-stem recording experiments}

In all, 112 spinal trigeminal tract fibers were recorded in normal adult rats and 132 fibers in adult rats that sustained transection of the IO nerve at least $60 \mathrm{~d}$ prior to the recording experiment.

Of the 112 fibers recorded in normal animals, $81(72.2 \%)$ units had IO receptive fields. As shown in Figure 4, 73.2\% of the IO units responded to innocuous vibrissal stimulation, $14.6 \%$ to guard hair deflection, $8.5 \%$ to gentle indentation of the skin, and $2.5 \%$ to noxious stimuli. When the analysis was restricted to those units with vibrissa receptive fields only $(n=61), 37.8 \%$ were found to be slowly adapting type I, $19.7 \%$ were slowly adapting type II, $37.8 \%$ were low velocity rapidly adapting, 3.3\% were high velocity rapidly adapting, and only $1.6 \%$ were nociceptive biascd.

In adult-lesioned animals, $81(61.3 \%)$ of the 132 recorded fibers had IO receptive fields. Of these, $38.2 \%$ responded to innocuous vibrissa stimulation, $29.6 \%$ to guard hair movement, $16.0 \%$ to gentle indentation of the skin, and $19.7 \%$ to noxious stimuli. Of the vibrissa-sensitive units, $16.1 \%$ were slowly adapting type I, $3.2 \%$ were slowly adapting type II, $45.2 \%$ were low velocity rapidly adapting, $35.5 \%$ were high velocity rapidly adapting, and $3.2 \%$ nociceptive biased. The dramatic relative 

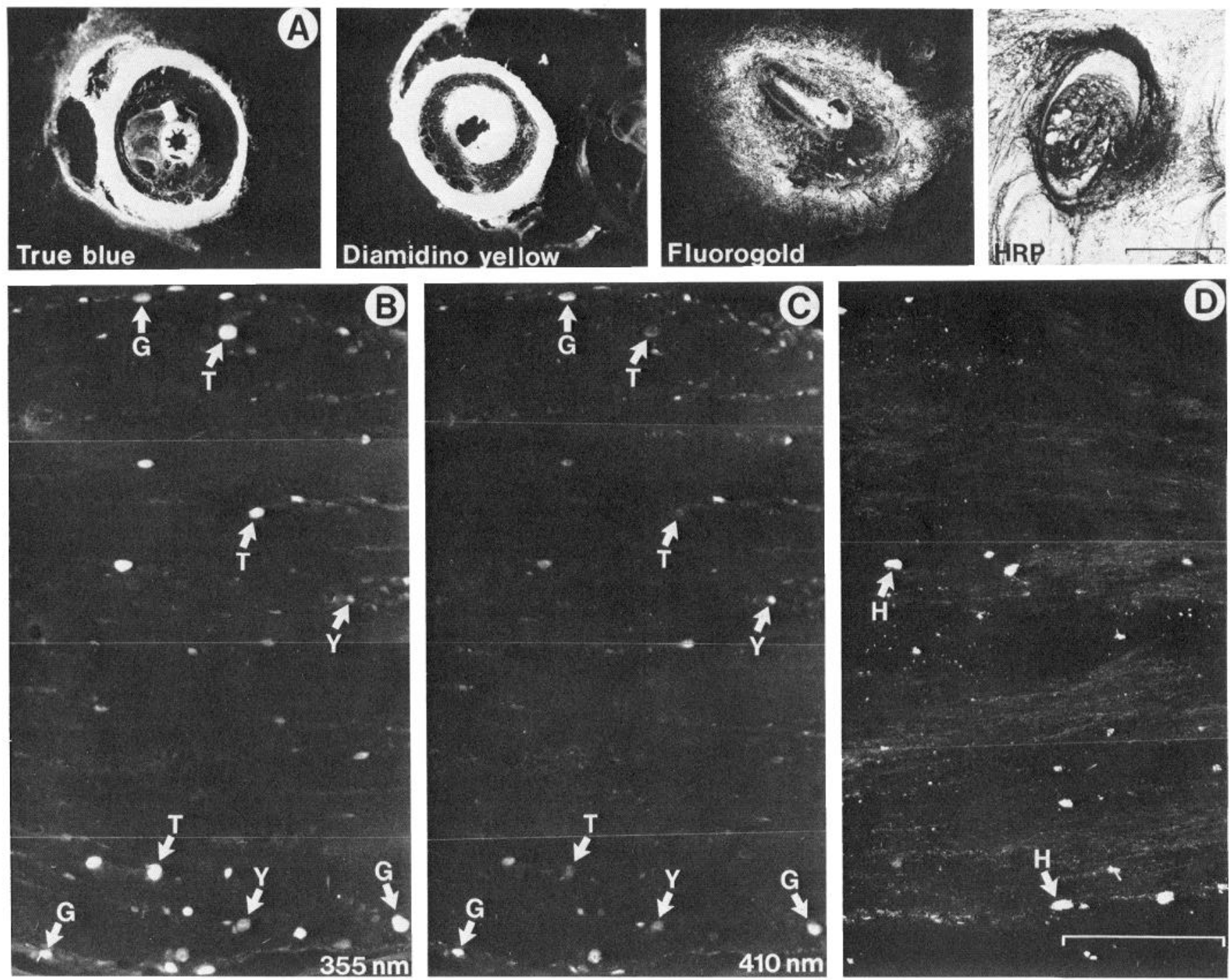

Figure 7. A, Examples of vibrissae injected with fluorescent tracers or HRP. These examples illustrate the accuracy of the injections, with very little tracer leaking into the surrounding connective tissue. Scale bar, $0.5 \mathrm{~mm}$. $B-D$, Longitudinal sections through the ganglion labeled by vibrissa injections shown in $A . B$ and $C$, Same section viewed with epifluorescence optics at an excitation wavelength of either 355 or $410 \mathrm{~nm}$. Examples of labeled cells are indicated by labeled arrows. $D$, A section through the ganglion adjacent to the section shown in $B$ and $C$. In this instance, darkfield optics are used to visualize examples of HRP-labeled neurons. See Figure 8 for a representation of all labeled cells in these sections. $G$, fluorogold; $T$, True blue; $Y$, diamidino yellow; $H$, HRP. Scale bar (in $D$ ), $250 \mu \mathrm{m}$.

increases in nociceptive and high velocity rapidly adapting units were statistically significant $\left(\chi^{2}\right.$ value $=11.66, p<0.01$ for nociceptive units; $\chi^{2}$ value $=22.32, p<0.01$ for velocity-biased vibrissa units).

As in the ganglion recording portion of this investigation, trigeminal spinal tract recordings in lesioned animals revealed a number of units with abnormal receptive fields. These included 2 units with nonadjacent multiple vibrissa receptive fields, 1 unit sensitive to movement of a mystacial vibrissa in maxillary territory and a patch of guard hairs in the mandibular region, and 10 units with no discernable receptive fields. Nine units in lesioned animals responded only to deep pressure in the region of the IO foramen, while no units with this receptive field were identified in normal adult rats.

\section{Topographic analysis}

Physiology. Figures 5 and 6 represent reconstructions of tungsten microelectrode tracks through 2 trigeminal ganglia in animals that sustained IO nerve transection. Careful examination of these and all other ganglion penetrations suggests the following conclusions regarding the organization of the trigeminal ganglion following this injury:

1. Units with maxillary receptive fields were found throughout the ophthalmic-maxillary region of the ganglion, with the highest concentration in the ventral aspect.

2. Ophthalmic units were most commonly encountered in medial tracks, and rarely in the most lateral tracks.

3. Units with mandibular receptive fields were most heavily represented in the dorsolateral portion of the ganglion.

Maxillary intradivisional topography was initially analyzed by plotting the receptive fields of the first and last recorded vibrissa-sensitive units in 19 dorsoventral penetrations of ganglia ipsilateral to the nerve transection (see Appendix). In normal ganglia, cells with caudal receptive fields were recorded dorsal to those with rostral receptive fields in approximately $92 \%$ of the tracks examined in this manner (Jacquin et al., 

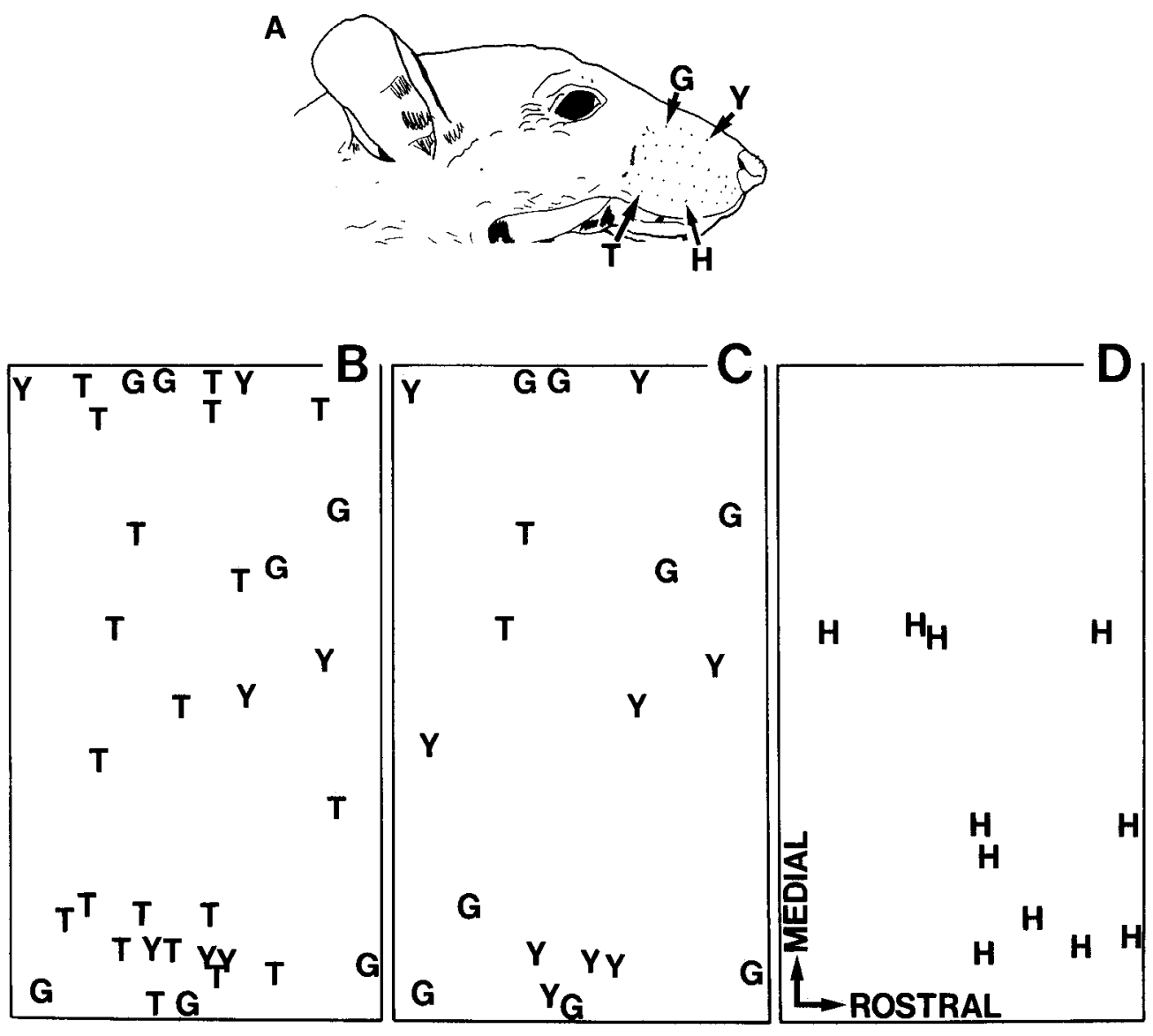

Figure 8. Schematic illustration of Figure 7, showing the sites of tracer injection and all the labeled cells seen in the sections discussed in that figure. $A$, The 4 vibrissae injected with the tracers (A1, A4, E1, and E4). B-D correspond to the analogous panels in Figure 7. All abbreviations are the same as those used in the previous figure.

$1986 \mathrm{c}$ ). In the present study of adult-lesioned ganglia, only $63 \%$ of the tracks displayed this topography, suggesting some loss of intradivisional order (Fisher's exact test, $p<0.05$ ).

Morphology. To pursue the question of altered maxillary intradivisional topography, we examined 6 rats that received injections of fluorescent tracers or WGA-HRP in the A1, A4, E1, and $\mathrm{E} 4$ vibrissae at least $60 \mathrm{~d}$ following adult $\mathrm{IO}$ transection. Figures 7 and 8 show the results of one such experiment. In this case, the A1 vibrissa was injected with fluorogold, A4 with diamidino yellow, E1 with True blue, and E4 with WGA-HRP. Ganglion cells labeled by retrograde transport of these tracers can be distinguished from each other by viewing the sections with a combination of episcopic fluorescence optics and brightor dark-field illumination. When this paradigm is used in normal animals, ganglion cells that innervate A-row vibrissae are located medially and neurons that supply caudal E-row hairs are lateral (Klein et al., 1987). This order was not evident in the adult-lesioned animals. As the plots of labeled cells in Figure 8 indicate, cells supplying dorsal vibrissae were located throughout the mediolateral extent of the ganglion, as were neurons innervating ventral hairs.

Though not shown in Figurc 7, we encountered occasional double-labeled ganglion cells in the tracer experiments. The number of double-labeled cells ( $2-4$ per ganglion) is consistent with data obtained in normal animals (Rhoades et al., 1987).

Effects of nerve transection on cell body size. To examine the effect of the lesion on ganglion cell body size we calculated corrected frequency distributions for the diameters of WGAHRP-labeled trigeminal ganglion cells labeled by injection of tracer into the intraorbital portion of the IO nerve in normal and adult-lesioned rats. Based on measurements of 478 cells in normal animals and 1122 neurons in animals that sustained IO transection, the data indicate that adult IO transection had no statistically significant effect on the average diameter of trigeminal ganglion cells that contribute axons to the regenerate nerve.

\section{Discussion}

The data obtained in this investigation indicate that transection of the IO nerve in the adult rat results in a number of abnormalities in the trigeminal primary afferent pathway. In the following discussion, each of the principal findings will be considered individually.

\section{Adult IO transection results in trigeminal ganglion cells with unusual receptive fields}

Recordings of primary afferent neurons in the trigeminal ganglion and trigeminal spinal tract ipsilateral to IO nerve transection disclosed units with discontinuous receptive fields, units sensitive to movement of both vibrissae and guard hairs, and a number of cells that responded only to deep pressure in the region of the IO foramen. Discontinuous receptive fields have been noted after peripheral nerve transection in a number of experimental (e.g., Horch, 1979; Terzis and Dykes, 1980; Jacquin et al., 1987) and clinical (e.g., Hallin et al., 1981) studies of primary afferent injury. In the present investigation, split receptive fields were recorded for units in both the trigeminal ganglion and in the trigeminal spinal tract. Axon misdirection, which is probably responsible for generation of discontinuous receptive fields, may be important in explaining the faulty sensory localization noted in clinical studies of peripheral nerve regeneration (see Terzis and Dykes, 1980; Hallin et al., 1981).

It is probable that most, if not all, of the units activated by 
deep pressure in the region of the IO foramen (the site of the transection injury) are responding to stimulation of axons in or near the neuroma which forms at this location following the lesion. Although many "neuroma" afferents exhibit spontaneous activity (see Burchiel, 1984; Meyer et al., 1985), only one of our cells manifested this property. In addition to cells which apparently ended in or near a neuroma, we were able to activate a number of ganglion cells with stimulating electrodes that had no discernable receptive field, suggesting that some ganglion cells may survive the loss of the distal portion of their peripheral processes following this type of injury.

\section{Nerve transection results in a shift in the receptive field properties of IO ganglion cells.}

We observed a significant decrease in the percentage of trigcminal ganglion cells responsive to low-threshold vibrissa stimulation with an increase in the number of guard hair and nociceptive afferents. Our previous study of the consequences of neonatal infraorbital IO nerve transection also disclosed a significant increase in nociceptive units (Jacquin et al., 1987). As noted in the introduction, most single-unit studies of the effects of peripheral nerve transection in humans have failed to explore this effect adequately. (Since the human investigations usually employ awake and unanesthetized subjects, this decision is understandable.) The increase in nociceptive units, however, may explain in part the numerous clinical accounts (e.g., Hallin et al., 1981) of painful sensations following recovery from nerve lesions.

The importance of the increase in guard hair units following nerve transection is less clear. Our previous study of neonatal IO injury found no change in the percentage of ganglion cells responsive to guard hair deflection. It has been shown, however, that the morphological consequences of IO nerve transection are less obvious in guard hair sensory receptors than vibrissa receptors (Renehan and Munger, 1986; Munger and Renehan, 1988). It is possible that regenerating IO axons encounter less difficulty in reinnervating guard hairs than vibrissae following the adult nerve injury.

Both the present brain-stem recording experiments and our previous study of the consequences of neonatal 10 injury revealed a statistically significant increase in the percentage of vibrissa units sensitive to rapid deflection of vibrissae (highvelocity afferents). The increase in the number of high-velocitysensitive cells was not statistically significant in the ganglion recording portion of the present study. Although it is currently not possible to provide a morphological explanation for shifts in the relative percentages of afferent modalities following IO lesion, it is worth noting that adult IO transection dramatically alters the structure of the vibrissa receptor apparatus (Renehan and Munger, 1986). It is possible that the abnormal primary afferent peripheral terminals noted in reinnervated vibrissae have receptive fields that appear identical to some of those seen in normal animals (e.g., nociceptive biased or high velocity rapidly adapting).

\section{IO nerve transection in the adult rat alters ganglionic topography}

When the positions of ophthalmic and mandibular units were plotted with respect to the mediolateral and dorsoventral axes of the trigeminal ganglion, we found essentially no change from the topography noted in normal ganglia (Jacquin et al., 1986c). Similar analysis of the IO vibrissa afferents suggested some topo- graphical abnormalities, but the observation was barely statistically significant. The retrograde labeling experiments, however, disclosed substantial ganglion reorganization following IO injury. The morphological studies, which are probably more accurate for this type of analysis, indicated that the mediolateral vibrissa topography seen in normal neonatal and adult rats (Klein et al., 1986, 1987) was almost completely eliminated. This alteration has also been demonstrated in neonatally lesioned rats (Klein et al., 1987). Whether or not the same mechanisms are responsible for reorganization in both the neonatal and adult ganglia remains to be established. It is possible that the abnormal ganglion topography seen in the present study is simply a result of misdirected regenerating axons. This suggests, for example, that ganglion cells that originally innervated A row vibrissae can supply vibrissae of any row following reinnervation of the mystacial pad. The resultant sensory misinformation, as interpreted by higher neural centers, could be very significant.

\section{Appendix}

Receptive fields of the first and last recorded vibrissa-sensitive cells in 19 dorsoventral penetrations through the ophthalmic-maxillary portion of trigeminal ganglia in rats subjected to adult $\mathrm{IO}$ nerve transection.

$\begin{array}{ll}\mathrm{B} 4, \mathrm{C} 4{ }^{a} & \mathrm{D} 5, \mathrm{~F} 6 \\ \mathrm{E} 2, \mathrm{C} 3 & \mathrm{C} 7, \mathrm{D} 3^{a} \\ \mathrm{E} 1, \mathrm{~B} 2 & \mathrm{D} 1, \mathrm{E} 2 \\ \mathrm{E} 2, \mathrm{E} 4 & \mathrm{D} 4, \mathrm{~F} 2^{a} \\ \mathrm{E} 2, \mathrm{~F} 3 & \mathrm{~F} 4, \mathrm{C} 5 \\ \mathrm{D} 3, \mathrm{~F} 1^{a} & \mathrm{~F} 2, \mathrm{~F} 6 \\ \mathrm{~B} 3, \mathrm{E} 1^{a} & \mathrm{~A} 2, \mathrm{D} 5 \\ \mathrm{~A} 1, \mathrm{~A} 2 & \mathrm{~B} 1, \mathrm{D} 7 \\ \mathrm{~B} 1, \mathrm{C}-\mathrm{D}^{a} & \mathrm{D}-\mathrm{E}, \mathrm{E} 3 \\ \mathrm{C} 5, \mathrm{C} 1^{a} & \\ { }^{a} \text { Those electrode tracks where the most dorsally isolated cell's receptive field was } \\ \text { not caudal to that of the most ventrally isolated cell. }\end{array}$

\section{References}

Aldskogius, H., and J. Arvidsson (1978) Nerve cell degeneration and death in the trigeminal ganglion of the adult rat following peripheral nerve transection. J. Neurocytol. 7: 229-250.

Arvidsson, J. (1979) An ultrastructural study of transganglionic degeneration in the main sensory trigeminal nucleus of the rat. J. Neurocytol. 8: 31-45.

Arvidsson, J., and H. Aldskogius (1977) Retrograde neuronal degeneration in the trigeminal ganglion of the rat. Light and electron microscopical observations. In Pain in the Trigeminal Region, D. J. Anderson and B. Matthews, eds., pp. 161-170, Elsevier/North-Holland Biomedical, Amsterdam.

Brown, A. G., and A. Iggo (1967) A quantitative study of cutaneous receptors and afferent fibres in the cat and rabbit. J. Physiol. (Lond.) 193: 707-733.

Burchiel, K. J. (1984) Effects of electrical and mechanical stimulation on two foci of spontaneous activity which develop in primary afferent neurons after peripheral axotomy. Pain 18: 249-265.

Burgess, P. R., and K. W. Horch (1973) Specific regeneration of cutaneous fibers in the cat. J. Neurophysiol. 36: 101-114.

Burgess, P. R., and E. R. Perl (1973) Cutaneous mechanoreceptors and nociceptors. In Handbook of Sensory Physiology, Vol. 2: Somatosensory System, A. Iggo, ed., pp. 29-78, Springer-Verlag, Heidelberg.

Fleiss, J. (1981) Statistical Methods for Rates and Proportions, Chap. 8.2, Wiley, New York.

Gottschaldt, K.-M., A. Iggo, and D. W. Young (1973) Functional characteristics of mechanoreceptors in sinus hair follicles in the cat. J. Physiol. (Lond.) 235: 287-315.

Grant, G., and J. Arvidsson (1975) Transganglionic degeneration in trigeminal primary sensory neurons. Brain Res. 95: 265-279.

Hallin, R. G., Z. Wiesenfeld, and U. Lindblom (1981) Neurophysio- 
logical studies on patients with sutured median nerves: Faulty sensory localization after nerve regeneration and its physiological correlates. Exp. Neurol. 73: 90-106.

Hawkins, G. L. (1948) Faulty sensory localization in nerve regeneration. An index of functional recovery following suture. J. Neurosurg. 5: 11-18.

Horch, K. (1979) Guidance of regrowing sensory axons after cutaneous nerve lesions in the cat. J. Neurophysiol. 42: 1437-1449.

Jacquin, M. F., and R. W. Rhoades (1983) Central projections of the normal and "regenerate" infraorbital ncrve in adult rats subjected to neonatal unilateral infraorbital lesions: A transganglionic horseradish peroxidase study. Brain Res. 269: 137-144.

Jacquin, M. F., and R. W. Rhoades (1985) Effects of neonatal infraorbital lesions upon central trigeminal primary afferent projections in rat and hamster. J. Comp. Neurol. 235: 129-143.

Jacquin, M. F., and P. Ziegler (1983) Trigeminal orosensation and ingestive behavior in the rat. Behav. Neurosci. 97: 62-97.

Jacquin, M. F., W. E. Renehan, R. D. Mooney, and R. W. Rhoades (1986a) Structure-function relationships in rat medullary and cervical dorsal horns. I. Trigeminal primary afferents. J. Neurophysiol. 55: $1153-1186$.

Jacquin, M. F., D. Woerner, A. M. Szczepanik, V. Riecker, R. D. Mooney, and R. W. Rhoades (1986b) Structure-function relationships in rat brainstem subnucleus interpolaris. I. Vibrissa primary afferents. J. Comp. Neurol. 243: 266-279.

Jacquin, M. F., W. E. Renehan, B. G. Klein, R. D. Mooney, and R. W. Rhoades (1986c) Functional consequences of neonatal infraorbital nerve section in rat trigeminal ganglion. J. Neurosci. 6: 3706-3720.

Klein, B. G., and R. W. Rhoades (1985) Representation of whisker follicle intrinsic musculature in the facial motor nucleus of the rat. J. Comp. Neurol. 232: 55-69.

Klein, B. G., G. J. MacDonald, A. M. Szczepanik, and R. W. Rhoades (1986) Topographic organization of peripheral trigeminal ganglionic projections in newborn rats. Dev. Brain Res. 27: 257-262.

Klein, B. G., W. F. Renehan, M. F. Jacquin, and R. W. Rhoades (1987) Anatomical consequences of neonatal infraorbital (IO) nerve transection upon the trigeminal ganglion and vibrissa follicle nerves in adult rat. J. Comp. Neurol. 268: 469-488.

Mackel, R., E. Kunesch, F. Waldor, and A. Struppler (1983) Reinnervation of mechanoreceptors in the human glabrous skin following peripheral nerve repair. Brain Res. 268: 49-65.

Mackel, R., E. E. Brink, and G. Wittkowsky (1985) Properties of cutaneous mechanosensitive afferents during the early stages of regeneration in man. Brain Res. 329: 49-69.

Mattson, D. (1981) Statistics. Difficult Concepts, Understandable Explanations, Lesson 3, Mosby, St. Louis.

McQuillan, W. M., J. M. M. Neilson, A. K. Boardman, and R. L. Hay (1971) Sensory evaluation after median nerve repair. Hand 3: 101111.

Mesulam, M.-M. (1978) Tetramethyl benzidine for horseradish peroxidase neurohistochemistry: A non-carcinogenic blue reaction product with superior sensitivity for visualizing neural afferents and efferents. J. Histochem. Cytochem. 26: 106-117.

Meyer, R. A., S. N. Raja, J. N. Campbell, S. E. Mackinnon, and A. L. Dellon (1985) Neural activity originating from a neuroma in the baboon. Brain Res. 325: 255-260.

Munger, B. L., and W. E. Renehan (1988) Degeneration and regeneration of peripheral nerve in the rat trigeminal system. III. Abnormal sensory reinnervation of rat guard hairs following nerve transection and crush. J. Comp. Neurol. (in press).

Orgel, M. G. (1982) Experimental studies with clinical application to peripheral nerve injury: A review of the past decade. Clin. Orthoped. Related Res. 163: 98-106.

Renehan, W. E., and B. L. Munger (1986) Degeneration and regeneration of peripheral nerve in the rat trigeminal system. II. Response to nerve lesions. J. Comp. Neurol. 249: 429-459.

Rhoades, R. W., J. Fiore, M. Math, and M. F. Jacquin (1983) Reorganization of trigeminal primary afferents following neonatal infraorbital nerve section in hamster. Dev. Brain Res. 7: 337-342.

Rhoades, R. W., N. L. Chiaia, R. D. Mooney, B. G. Klein, W. E. Renehan, and M. F. Jacquin (1987) Reorganization of the peripheral projections of the trigeminal ganglion following neonatal transection of the infraorbital nerve. Somatosen. Res. 5:35-62.

Rosene, D. L., and M.-M. Mesulam (1978) Fixation variables in horseradish peroxidase neurohistochemistry. I. Effects of fixation time and perfusion procedures upon enzyme activity. J. Histochem. Cytochem. 26: $28-39$.

Smolen, A. J., L. L. Wright, and T. J. Cunningham (1983) Neuron numbers in the superior cervical sympathetic ganglion of the rat: A critical comparison of methods for cell counting. J. Neurocytol. 12: $739-750$.

Terzis, J. K., and R. W. Dykes (1980) Reinnervation of glabrous skin in baboons: Properties of cutaneous mechanoreceptors subsequent to nerve transection. J. Neurophysiol. 44: 1214-1225. 